\title{
O papel do farmacêutico no controle do uso racional de antimicrobianos em drogarias
}

\author{
The role of pharmaceutical in control of the rational use of antimicrobials in drugs
}

\author{
Kelly Lustosa Barbosa ${ }^{1^{*} \bullet}$, Ciro José Sousa de Carvalho ${ }^{2}$ \\ ${ }^{1}$ Graduanda de Farmácia, Faculdade de Palmas, Palmas, Tocantins, Brasil. ${ }^{2}$ Professor Adjunto I, Faculdade de Palmas, Palmas, \\ Tocantins, Brasil. *Autor para correspondência. E-mail: kelly.lust@hotmail.com
}

\begin{abstract}
Resumo: Introdução: A capacidade de resistência bacteriana aos antibióticos é caracterizada como possibilidade de uma bactéria de sobreviver em concentrações de antibióticos que inibem outras da mesma espécie. Revisão: Este estudo trata-se de uma revisão de literatura a partir da síntese dos principais estudos publicados na LILACS e MEDLINE que fazem parte da Base de dado da coleção Biblioteca Virtual de Saúde - BVS. É cada vez mais progressivo o aumento de microrganismos patogênicos que resistem aos antimicrobianos devido ao seu potencial infeccioso. Uma vez que o antimicrobiano é prescrito pelo médico responsável, compete ao farmacêutico a instrução para a administração do mesmo, o que irá proporcionar maior segurança e eficiência durante o tratamento do paciente. Discussão: Para diminuir a incidência de resistência aos antibióticos devido ao uso inadequado é importante que o paciente tenha as informações adequadas principalmente no que se refere a não fazer uso da automedicação. Considerações finais: A ação farmacêutica é importante na orientação correta dos antimicrobianos sendo um grande desafio. É fundamental que participe de modo ativo em relação ao uso dos medicamentos e repassar ao paciente as informações necessárias sobre a antibioticoterapia.
\end{abstract}

Palavras-chave: antimicrobianos, resistência, farmacêutico.

\begin{abstract}
Introduction: The ability of bacterial resistance to antibiotics is characterized as the possibility of a bacterium to survive in concentrations of antibiotics that inhibit others of the same species. Review: This study is a literature review based on the synthesis of the main studies published in LILACS and MEDLINE that are part of the Virtual Health Library - VHL collection database. The increase in pathogenic microorganisms that resist antimicrobials due to their infectious potential is increasingly progressive. Once the antimicrobial is prescribed by the responsible physician, the pharmacist is responsible for instructing the administration of the same, which will provide greater safety and efficiency during the patient's treatment. Discussion: To reduce the incidence of antibiotic resistance due to inappropriate use, it is important that the patient has adequate information, especially with regard to not using self-medication. Final considerations: The pharmaceutical action is important in the correct orientation of antimicrobials, being a great challenge. It is essential that you actively participate in the use of medications and provide the patient with the necessary information about antibiotic therapy.
\end{abstract}

Keywords: antimicrobials, resistance, pharmaceutical.

\section{Introdução}

A resistência antimicrobiana está demonstrada na literatura como consequência da relação de muitos organismos com seu ambiente e a maioria das bactérias desenvolveram mecanismos para superar sua ação para sobreviver (Munita \& Arias, 2016). É uma ameaça à saúde e ao êxito da terapêutica com antimicrobianos podendo estar também relacionada com a concentração do antibiótico utilizado no tratamento infeccioso (Giono-Cerezo et al., 2020).

Vários estudos demonstram que o impacto da resistência bacteriana ocorre mais no âmbito hospitalar entre pacientes internados. Nesse contexto, a dose de antibiótico deve ser suficiente para impedir a proliferação de micro-organismos e não ser tóxico às células humanas, pois, a resistência antimicrobiana pode ter uma ligação direta com a quantidade de antimicrobianos ingeridos (Mitrel et al., 2017).

No âmbito da farmácia, Marques et al. (2015), ressalta que, o paciente somente retira da farmácia o medicamento mediante prescrição médica e recebe as orientações pertinentes quanto ao uso do mesmo, pois é ele quem administrará o medicamento. 
A manipulação dos antimicrobianos no que se refere ao controle do seu em drogarias se constitui uma função do farmacêutico e busca garantir à população não somente o acesso aos medicamentos considerados essenciais, mas também assegurar a qualidade e eficácia deles assim como a promoção do seu uso racional. A prescrição correta de antimicrobianos tem benefícios significativos e reduz o desenvolvimento de resistência aos antimicrobianos (Sikkens et al., 2017).

Ao fazer uso do antibiótico o paciente deve ter conhecimento de alguns elementos importantes dentre eles, o uso correto da dosagem indicada na receita, a interferências dos alimentos, a interação com outros medicamentos, o conhecimento de reações adversas e as formas de armazenar e conservar os medicamentos (Lima-Dellamora et al. 2017).

As informações contidas neste trabalho de revisão bibliográfica busca apontar a relevância do trabalho do farmacêutico no controle do uso racional de antimicrobianos em drogarias.

A pesquisa bibliográfica para este estudo foi realizada na base de dados da Biblioteca Virtual de Saúde e utilizou-se os descritores antimicrobiano, resistência, farmacêutico.

\section{Revisão}

Esta pesquisa é uma revisão de literatura realizada a partir da síntese dos principais estudos publicados na LILACS e MEDLINE que fazem parte da Base de dado da coleção Biblioteca Virtual de Saúde - BVS. Os critérios de inclusão dos artigos foram as publicações dos últimos 10 anos (2011-2021), os descritores utilizados foram: antimicrobiano, resistência, farmacêutico.

A resistência microbiana é definida pela a Organização Mundial da Saúde (OMS) como a capacidade de um microrganismo impossibilitar a atuação de um antimicrobiano (BRASIL, 2018). A resistência bacteriana aos antibióticos é a capacidade de uma bactéria de sobreviver em concentrações de antibióticos que inibem outras da mesma espécie (Alós, 2015).

As bactérias, em um processo provavelmente pressionado pelo aumento do uso de antimicrobianos na prática clínica, desenvolveram estratégias complexas e criativas para contornar o ataque de antibióticos (Munita \& Arias, 2016).

Nas considerações de Rocha (2016), o desenvolvimento de microrganismos patogênicos resistentes aos antimicrobianos existentes se torna crescente devido ao seu potencial infeccioso e tem sido considerado por profissionais e pesquisadores da área da saúde como um fator merece atenção e estudos constantes.

Existe um aumento no número de microrganismos resistentes em todo o mundo e os padrões dessa resistência variam entre os países. Houve um aumento significativo em toda a Europa nas porcentagens de Klebsiella pneumoniae resistente a fluoroquinolonas, cefalosporinas de terceira geração e aminoglicosídeos e também resistência combinada a todos os três grupos de antibiótico (Karam, 2016).

Consequentemente, é fundamental investigar sob quais condições e em que medida ocorre a adequação ambiental para resistência e também compreender os riscos, para evitar que patógenos resistentes, bem como novos genes de resistência, cheguem aos humanos (Bengtsson-Palme et al., 2018).

Dessa forma, mesmo com o uso de forma adequada como a utilização correta do antibiótico, a dose apropriada, o devido intervalo entre as doses e a duração do tratamento é importante ressaltar que também pode ocasionar resistência antimicrobiana, o que pode ser considerado uma das preocupações mundiais, pois, ainda não há outro medicamento com o mesmo potencial e capacidade de suprir com os mesmos mecanismos de ação os antimicrobianos (Boaventura et al., 2019).

Em relação a resistência ao uso indiscriminado é importante ressaltar que acontece desde o descobrimento da penicilina e como consequência, pois, muitas bactérias patogênicas foram se adaptando a uma série de componentes farmacológicos que eram utilizados com objetivo de eliminá-las, fazendo com que seus efeitos se tornassem ineficientes (Holmes et al., 2016).

Por serem receitados em grandes quantidades e, também são muito usados na automedicação a utilização dos antibióticos antimicrobianos pode afetar de forma significativa a microbiota do paciente que o utiliza (Gonçalves et al., 2016).

Uma vez que o antimicrobiano é prescrito pelo médico responsável, compete ao farmacêutico a orientação e acompanhamento na sua administração contribuindo com a maior segurança e eficiência no tratamento do paciente (Estrela, 2018). É importante destacar que, a profilaxia incorreta, no que se refere a doses e horários de administração, leva a resistência bacteriana (Donizete, 2020).

Erros na administração das medicações têm uma implicação expressiva nos pacientes no que se refere a mortalidade, reações adversas, aumento do tempo de internação hospitalar e ainda elevação dos custos financeiros para os sistemas de saúde (Araújo, 2019). 
Outros pontos a se considerar são as informações incompletas nas prescrições o que representa falhas de comunicação entre os profissionais de saúde envolvidos no processo de prescrição e administração de medicamentos que podem influenciar de forma negativa na farmacoterapia do uso dos antibióticos (Carvalho et al., 2020).

Apesar do uso correto dos antimicrobianos causar resistência, o uso de forma inadequada é o principal fator de risco para a colonização ou infecção por bactérias resistentes, além do mais, a falta de novos medicamentos com a mesma função terapêutica ocasiona a resistência de tais medicamentos (Gonçalves, 2016).

Para minimizar a resistência aos antibióticos é importante considerar a orientação de uso dos antimicrobianos pelo farmacêutico pois é fundamental este profissional ter atitudes e habilidades que permitam interagir com o paciente, de forma a orientar sobre o uso adequado dos antimicrobianos, contribuindo para o bom resultado farmacoterapêutico (Novaretti et al., 2014).

Nos estudos de Franco et al. (2015), são várias as atribuições do farmacêutico que trabalham em farmácias e drogarias, dentre elas, a função de transmitir informações sobre o uso inadequado, as interações medicamentosas, prestar assistência através de intervenções que direcionem o paciente quanto ao uso correto dos medicamentos, sobretudo advertindo sobre a importância de ser ingerido no horário prescrito pelo médico e a forma como armazenar o fármaco adequadamente, e em casos de ações adversas procurar os serviços de saúde.

\section{Discussão}

Apesar do aumento da resistência aos antimicrobianos ainda não existe outro medicamento com a mesma função para substituí-lo. Nesse sentido, é importante que o seu uso seja realizado de forma adequada de acordo a prescrição médica.

A revisão de literatura apontou que a maior incidência de resistência aos antibióticos ocorre nos hospitais com os pacientes internados. É importante ressaltar que também o uso de forma adequada, a dose apropriada, o intervalo correto entre as doses e a duração do tratamento pode ocasionar a resistência.

Para diminuir a incidência de resistência aos antibióticos devido ao uso incorreto é necessário que o paciente tenha as informações corretas essencialmente no que se refere a não fazer uso da automedicação.

No âmbito da farmácia, ao comprar o antibiótico o paciente deve ter conhecimento sobre cumprimento da dosagem, a interação com outros fármacos, a observação de reações que causam desconforto e as formas de conservar os medicamentos, cabendo ao farmacêutico a orientação e assistencia na administração do mesmo.

\section{Considerações finais}

A resistência aos antibióticos é considerada uma preocupação mundial. Como apontou a revisão de literatura realizada ainda não foi possível substituir os antibióticos.

Vários estudos apontam que essa resistência é uma consequência natural, contudo, o seu uso indiscriminado pode colaborar consideravelmente para o crescimento da resistência antimicrobiana.

Dessa forma, a atual ação farmacêutica é importante na orientação correta dos antimicrobianos sendo um grande desafio para o farmacêutico, pois, é fundamental que participe de modo ativo nas demandas do paciente em relação ao uso dos medicamentos e repassar as informações necessárias sobre a antibioticoterapia e zelar pelo uso racional.

Com isso, espera-se que o paciente faça o uso correto do antimicrobiano evitando assim uma possível resistência futura, pois o uso indiscriminado e a falta de informação facilitam a má administração do medicamento pelo paciente, colaborando assim para o surgimento da resistência bacteriana.

\section{Referências}

Araújo, P. R., Lima, F. E. T., Ferreira, M. K. M., Oliveira, S. K. P., Carvalho, R. E. F. L., \& Almeida, P.C. 2019. Medication administration safety assessment tool: construction and validation. Revista Brasileira de Enfermagem, 72(2), 329-36.

Alós, J.-I. 2015. Resistencia bacteriana a los antibióticos: una crisis global. Enfermedades Infecciosas y Microbiología Clínica, 33(10), 692-699.

Bengtsson-Palme, J., Kristiansson, E., \& Larsson, D. G. J. 2018. Environmental factors influencing the development and spread of antibiotic resistance. FEMS Microbiology Reviews, 42(1), 68-80. 
Boaventura, J. E. M., Cordeiro, A. L. A. O., Barros, C. S. M. A., Moreira, B. S. G., Lobo, J. O., \& Pedreira, L. C. 2019. Infecções de sítio cirúrgico: incidência e perfil de resistência antimicrobiana em unidade de terapia intensiva. Revista Baiana de Enfermagem, 33, e33595.

Brasil. Uso de Medicamentos e Medicalização da Vida: recomendações e estratégias. Ministério da Saúde Secretaria de Ciência Tecnologia e Insumos Estratégicos Departamento de Assistência Farmacêutica e Insumos Estratégicos. Brasília: Ministério da Saúde, 2018.

Carvalho, H. E. F., Sousa, A. F. L., Almeida, C. A. P. L., Moura, M. E. B., Andrade, D., \& Valle, A. R. M. C. 2020. Análise de prescrições de antimicrobianos na Atenção Primária à Saúde. Revista da Escola de Enfermagem da USP, 54, e03607.

Donizete, A. L., Oliveira, J., Romeiro, J. R., \& Moreno, A. H. 2020. Importância do uso racional de medicamentos na administração de antibióticos injetáveis. Revista Enfermagem - CuidArte, 14(2).

Marques, U. C. F., Deuschle, R. A. N., \& Deuschle, V. C. K. N. 2015. Avaliação da prevalência da dispensação de antimicrobianos na farmácia pública do município de Cruz Alta -RS. Revista Eletrônica de Farmácia, $12(2), 1-15$.

Estrela, T. S. 2018. Resistência antimicrobiana: enfoque multilateral e resposta brasileira. Assessoria de Assuntos Internacionais de Saúde (MS), 307-327.

Franco, J. M. P. L., Mendes, R. D. C., Cabral, F. R. F., \& Menezes, C. D. A. 2015. O papel do farmacêutico frente à resistência bacteriana ocasionada pelo uso irracional de antimicrobianos. Semana Acadêmica Revista Científica, 1(72), 1-17.

Gonçalves, P. B., Corradi, M. F. Dal Ben C., Okamura, M. N., Hemmi, M. S., \& Pizzo, V. R. P. Alertas para uso de antimicrobianos terapêuticos. In XV Congresso Brasileiro de Informática em Saúde 27 a 30 de novembro, 2016. Goiânia, GO. Disponível em: http://www.jhi-sbis.saude.ws/ojs-jhi/index.php/jhi-sbis. Acesso em: ago. 2021.

Giono-Cerezo, S., Santos-Preciado, J. I., Morfín-Otero, M. D. R., Torres-López, F. J., \& Alcántar-Curiel, M. D. 2020. Antimicrobial resistance. Its importance and efforts to control it. Gaceta Medica de Mexico, 156(2), 171-178.

Holmes, A. H., Moore, L. S. P., Sundsfjord, A., Steinbakk, M., Regmi, S., Karkey, A., Guerin, P. J., \& Piddock, L. J. V. 2016. Understanding the mechanisms and drivers of antimicrobial resistance. The Lancet, 387(10014), 176-187.

Lima-Dellamora, E. C., Osorio-de-Castro, C. G. S., Madruga, L. G. S. L., \& Azeredo, T. B. 2017. Utilização de registros de dispensação de medicamentos na mensuração da adesão: revisão crítica da literatura. Cadernos de Saúde Pública, 33(3), e00136216.

Mitrel, G. S., Silva, S. A. B., Silva, G. A. B., Rezende, M. M. P., \& Sousa Junior, J. R. 2017. Perfil de prescrição de antimicrobianos nas unidades básicas de saúde conveniadas com a universidade de Itaúna/MG. Revista Médica de Minas Gerais, 27, e-1875.

Munita, J. M., \& Arias, C. A. 2016. Mechanisms of Antibiotic Resistance. In: Kudva, I. T., Cornick, N. A., Plummer, P. J., Zhang, O., Nicholson, T. L., Bannantine, J. P., \& Bellaire, B. H. Virulence Mechanisms of Bacterial Pathogens, $5^{\text {th }}$ ed, American Society for Microbiology.

Novaretti, M. C. Z., Aquino, S., \& Piscopo, M. R. 2014. Controle de vendas de antibióticos no Brasil: análise do efeito dos atos regulatórios no uso abusivo pelos consumidores. Revista Acadêmica São Marcos, 4(2), 2539.

Sikkens. J. J., Agtmael, M. A., Peters, E. J. G., Lettinga, K. D., Kuip, M., Vandenbroucke-Grauls, C. M. J. E., Wagner, C., \& Kramer, M. H. H. 2017. Behavioral Approach to Appropriate Antimicrobial Prescribing in Hospitals. The Dutch Unique Method for Antimicrobial Stewardship (DUMAS) Participatory Intervention Study. Jama Internal Medicine, 177(8), 1130-1138.

\section{Minicurrículo}

Kelly Lustosa Barbosa. Graduanda em Farmácia, Faculdade de Palmas-FAPAL.

Ciro José Sousa de Carvalho. Graduado em Medicina Veterinária (UFPI), Mestre em Ciência Animal com ênfase em toxicologia pela Universidade Federal do Piauí (UFPI) com participação em Programa de 
Cooperação Acadêmica (PROCAD) pela Universidade Federal de Minas Gerais (UFMG) -2012 e Doutor em Ciência Animal com ênfase em Diagnóstico precoce de metástases em câncer de mama pela Universidade Federal do Piauí (UFPI) em 2016. Tem experiência em Docência no Ensino Superior nas áreas: Patologia Geral, Pesquisa Clínica, Anatomia Humana, Anatomia Comparada, Epidemiologia e Saúde Pública, Imunologia, Imunopatologia, Fisiologia aplicada, Patologia Veterinária Especial, Anatomia Veterinária, Oncologia Veterinária, clínica médica de cães e gatos, Toxicologia e Plantas Tóxicas. Atua como Médico Veterinário prestador de serviços em Diagnóstico Clínico e Citopatológico de neoplasias malignas e benignas em animais de companhia, realiza tratamento quimioterápico antineoplásico em animais. Consultor "Ad hoc" de revistas nacionais indexadas. Autor e coautor em diversas revistas indexadas nacionais e internacionais. Professor Conteudista/Tutor EAD em cursos de pós-graduação nas áreas de Saúde e Medicina Veterinária.

Como citar: Barbosa, K.L., \& Carvalho, C.J.S. 2021. O papel do farmacêutico no controle do uso racional de antimicrobianos em drogarias. Pubsaúde, 7, a170. DOI: https://dx.doi.org/10.31533/pubsaude7.a170

Recebido: 28 abr. 2021.

Revisado e aceito: 19 mai. 2021.

Conflito de interesse: os autores declaram, em relação aos produtos e companhias descritos nesse artigo, não ter interesses associativos, comerciais, de propriedade ou financeiros que representem conflito de interesse.

Licenciamento: Este artigo é publicado na modalidade Acesso Aberto sob a licença Creative Commons Atribuição 4.0 (CC-BY 4.0). 